\title{
A Simplified Procedure for Reliability Estimation of Underground Concrete Barriers against Normal Missile Impact
}

\author{
N. A. Siddiqui \\ Department of Civil Engineering, King Saud University, Riyadh, Saudi Arabia \\ Received 6 Jul 2008; accepted 27 June 2010 \\ طريقة مبسطة لتقدير إعتمادية الحواجز الخزسانية المدفونة تحت الأرض لمقاومة إصطدام المقذوفات العادية \\ الخلاصة : تستخدم الحواجز الخرسانية المدفونة تحت الأرض على اعماق كبيرة تحت التربة لحماية المنشآت الإستراتيجية مثل محطات الطاقة النووية

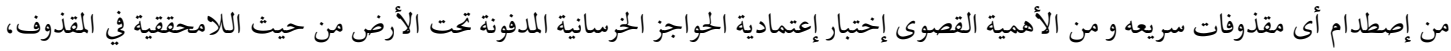

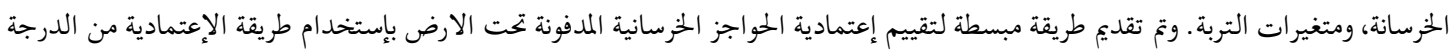

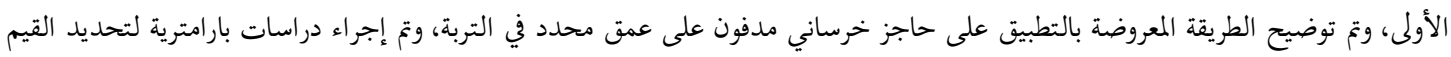 \\ التصميمية ليكون الحاجز باعلى إعتمادية مطلوبة. \\ المفردات المفتاحية : مقذوف، إختراق التربة، حواجز خرسانية، الإعتمادية الإنشائية، طريقة الإعتمادية من الدرجة الأولى.

\begin{abstract}
Underground concrete barriers are frequently used to protect strategic structures like Nuclear power plants (NPP), deep under the soil against any possible high velocity missile impact. For a given range and type of missile (or projectile) it is of paramount importance to examine the reliability of underground concrete barriers under expected uncertainties involved in the missile, concrete, and soil parameters. In this paper, a simple procedure for the reliability assessment of underground concrete barriers against normal missile impact has been presented using the First Order Reliability Method (FORM). The presented procedure is illustrated by applying it to a concrete barrier that lies at a certain depth in the soil. Some parametric studies are also conducted to obtain the design values which make the barrier as reliable as desired.
\end{abstract}

Keywords: Missile, Soil-penetration, Projectiles, Concrete barriers, Structural reliability; FORM

\section{Introduction}

The reliability of any structure is the probability of its survival under possible extreme loadings. the If structure is a concrete barrier that lies at a certain depth in the soil, and a missile (a rigid projectile) impacts the top of the soil cover normally, and subsequently after penetrating the soil cover completely hits the barrier with certain striking velocity then the reliability of the barrier can be described as having the probability of not getting penetrated the the missle. In a deterministic sense, if the estimated depth of penetration is small compared to the thickness of the con-

*Corresponding author's e-mail: nadeem@ksu.edu.sa crete barrier, the barrier may be considered safe. However, this safety is not absolute safety but "probable safety ". It is "probable safety" because all material and geometric properties have some inherent variability, which makes determination of absolute safety almost impossible. An effort can only be made to design the barrier with a desired reliability for a given range and type of missile impact. In the recent past, (Choudhary et al. 2002; Siddqui et al. 2002, 2003 and Siddiqui 2003) carried out reliability assessments of different types of target under missiles, projectiles or jet aircraft impacts. 
Determination of the reliability of underground concrete targets very much depends on estimation of an damages (eg. penetration) caused in these targets due to missile impact. In the past, (Forrstal and Luk 1992; Siddiqui and Abbas 2002 and Siddiqui et al. 2006) studied mechanics of missile penetration in soil targets and (Forrestal et al. 1994, 1996, 2003; Frew et al. 1998, 2006 and Khan et al. 2003) studied the penetration in concrete targets. In all instances, they determined expressions for depths of penetration and verified the analytical results with experimental findings.

A careful review of the literature reveals that although considerable material is available on the mechanics of missile penetration into soil and concrete targets, studies on the reliability assessment of underground concrete targets are very scanty. Further, the relevant work, eg. (Chaoudhury et al. 2002 and Siddiqui et al. 2002) is on concrete targets which are buried under rock. There appears to be no work, however, on the reliability assessment of concrete barriers that are buried under the soil and hit by a missile after completely penetrating the soil cover. With this in mind, the present study, a procedure has been proposed for the reliability assessment of concrete barriers that lie at a certain depth in the soil, and a missile (rigid projectile) impacts the top of the soil cover normally, and, subsequently after completely penetrating the soil cover hits the concrete barrier with a certain striking velocity. For this purpose, using expressions available in the literature, the striking velocity of a missile at any depth of soil has been derived and then expressions for the depths of penetration in the crater and tunnel regions of a concrete barrier have been deduced. These depths of penetration have been employed for the derivation of limit state functions. Using the derived limit state functions, the reliability assessment of an underground concrete barrier has then been carried out through the First Order Reliability Method (Nowak and Collins 2000). The presented procedure was illustrated by applying it to a concrete barrier that lay at a certain depth in the soil. Some parametric studies were also conducted to obtain the design values which make the barrier as reliable as desired.

\section{Problem Formulation}

In the present study, an underground concrete barrier is assumed as failed if a missile completely penetrates the concrete thickness. This is due to the fact that things of importance are kept under these barriers, and a missile can cause considerable damage to them only if it penetrates the concrete barrier completely. To derive limit state functions under the above criterion of failure, first we require expressions for depths of pen- etration in a concrete barrier due to missile impact. In the present study, these depths of penetration have been derived under the following assumptions and idealizations:

1. The missile is rigid, ie. its deformation is negligible, and only soil and concrete deformations have been considered.

2. The missile is considered to be of ogival nose shape.

3. The impact of the missile is normal and axi-symmetric.

4. The missile does not carry any warhead and so no explosion has been considered.

5. The rear face scabbing of the concrete target, due to missile penetration, is negligible.

In the present study we are concerned with the reliability analysis of a buried concrete target which is considered failed if the missile penetrates it completely. Hence, conditions that lead to a higher depth of barrier penetration will be a conservative estimate for reliability calculations. Assumption (1) and (3) provide higher depths of penetration than if the missile deforms or impacts the target at a certain angle other than normal (ie. oblique impact).

For most targets, an ogival-nose-shaped missile penetrates more than conical nose shape missile; hence, assumption (2) is also on the conservative side (Siddiqui and Abbas 2002).

A missile carrying a warhead destroys the things behind the concrete barrier in two stages: first it fully penetrates the concrete barrier and then it explodes its warhead to destroy everything behind the barrier. If the missile fails to penetrate the barrier, the destruction behind the concrete barrier may not be significant. For this reason, in assumption (4), the explosion of the warhead is neglected and the penetration of the concrete barrier has been considered as the failure of the concrete barrier.

As the subject of the present study is related to the concrete barrier's penetration, rear face scabbing is ignored in assumption (5).

Under the above assumptions and idealizations, when a missile impacts a uniform soil target at normal incidence (Fig. 1) with an initial velocity $V_{o}$, and proceeds through the soil cover with velocity $V_{z}$ at any depth $z$, its nose experiences an axial force $F_{Z}$. Forrestal and Luk (1992) have developed the following expression for this axial force $F_{z}$ as

$$
F_{z}=\alpha_{s}+\beta_{S} V_{z}^{2}
$$

where, $\alpha_{\mathrm{s}}$ and $\beta_{\mathrm{s}}$ are defined in Eq. (A-1) (Appendix).

From Newton's second law the equation for the rigid body motion of a missile with a mass $m$ is given 
as

$$
m \frac{d V_{z}}{d t}=-\left(\alpha_{S}+\beta_{S} V_{z}^{2}\right)
$$

When a missile hits a concrete barrier, lying at a depth of $z$ in the soil with a striking velocity $V_{z}$ it creates a conical-shaped crater region with a depth of about two missile shank diameter ie. 4a, followed by a circular cylinder-shaped tunnel region with a diameter nearly equal to the shank diameter ie. $2 a$, (Forrestal et al. 1994, 1996). The depths of penetration in the crater region $z_{s c}$ and tunnel region $z_{f t}$ from the concrete surface can be expressed as

$$
\begin{aligned}
& z_{S c}=\left(\frac{V_{z}}{\omega}\right) \sin \omega t \\
& \text { in which, } \omega=\sqrt{\frac{c}{m}} \\
& \text { and } c=\frac{\pi a\left(S f_{c}+N \rho_{c} v_{c}^{2}\right)}{4}
\end{aligned}
$$

where,

$S=$ a parameter (Frew et al. 1998)

$f_{c}=$ unconfined compressive strength of concrete;

$N=$ dimensionless constant that depends on missile caliber radius head (Fig. 3) $\Psi$

$$
=\frac{8 \psi-1}{24 \psi^{2}}
$$

$\rho_{c}=$ density of concrete target; and

$V_{c}=$ rigid body missile velocity at $z_{s c}=4 a$, it is given by

$$
=\sqrt{\frac{m v_{z}^{2}-4 \pi a^{3} S f_{c}}{m+4 \pi a^{3} N \rho_{c}}}
$$

Substituting expression of $V_{z}$ from Eq. (A-13) in the above equation we get

$$
V_{c}=\sqrt{\frac{m\left(\frac{\alpha_{S}}{\beta_{s}}\right) \tan ^{2} B^{\prime}-4 \pi a^{3} S f_{c}}{m+4 \pi a^{3} N \rho_{c}}}
$$

Putting this value of $V_{c}$ of Eq. (8) in Eq. (5), we get $c$ as

$$
\mathrm{c}=\frac{\pi a}{4}\left[S f_{c}+N \rho_{c}\left\{\frac{m\left(\frac{\alpha_{s}}{\rho_{s}}\right) \tan ^{2} B^{\prime}-4 \pi a^{3} S f_{c}}{m+4 \pi^{3} N f_{c}}\right\}\right]
$$

Putting this value of $c$ from Eq. (9) in Eq. (4) we get

$$
\omega=\frac{1}{2} \sqrt{\frac{\pi a}{m}\left[S f_{c}+N \rho_{c}\left\{\frac{m\left(\frac{\alpha_{S}}{\beta_{S}}\right) \tan ^{2} \beta^{\prime}-4 \pi a^{3} S f_{c}}{m+4 \pi a^{3} N \rho_{c}}\right\}\right.}
$$

Substituting Eq. (10) for $\omega$ and Eq. (A-11) for $t$ into Eq. (3) we have

$$
\begin{aligned}
z_{S c}= & \left(\frac{\alpha_{S}}{\beta_{S}}\right)^{1 / 2} \tan B^{\prime} \times 2 \sqrt{\frac{m}{\pi a\left[S_{f_{c}}+N \rho_{c} \times K^{\prime}\right]}} \times \\
& \operatorname{Sin}\left[\left\{\frac{1}{2} \sqrt{\frac{\pi a}{m}\left(S f_{c}+N \rho_{c} \times K^{\prime}\right)}\right\} \times \frac{m}{\left(\alpha_{S} \beta_{S}\right)^{1 / 2}}\left(A^{\prime}-B^{\prime}\right)\right]
\end{aligned}
$$

where, $K^{\prime}=\frac{m\left(\frac{\alpha_{s}}{\beta_{s}}\right) \tan ^{2} B^{\prime}-4 \pi a^{3} S f_{c}}{m+4 \pi a^{3} N \rho_{c}}$

If the depth of concrete target is $d_{c}$, then the limit state function (or safety margin) $g(\underline{X})$ can be written as

$$
g(\underline{X})=d_{c}-z_{s c}
$$

Substituting $z_{s c}$ from Eq. (11) we have

$$
g(\underline{X})=d c-\left[\begin{array}{c}
2 \tan B^{\prime} \sqrt{\frac{m \alpha_{S}}{\pi a\left[S f_{c}+N \rho_{c} \times K\right] \beta_{S}}} \\
\times \operatorname{Sin}\left\{\begin{array}{c}
\frac{1}{2} \sqrt{\frac{\pi a}{m}\left(S f_{c}+N \rho_{c} \times K\right)} \\
\times \frac{m}{\left(\alpha_{S} \beta_{S}\right)^{1 / 2}}\left(A^{\prime}-B^{\prime}\right)
\end{array}\right\}
\end{array}\right]
$$

where $(\underline{X})$ denotes the vector of random variables given by

$\underline{X}=\left(m, a, \eta^{*}, V_{0}, \lambda, d_{g}, \rho_{c}, S, f_{c}, d_{c}, E, \psi, \mu, \rho_{0}\right)$

where, $d_{g}=z=$ depth of soil above the concrete surface (Fig. 1).

The final depth of penetration in the crater region is where the missile velocity becomes zero subject to a maximum depth of $4 \mathrm{a}$. It is due to the fact that beyond 4a the tunnel region begins and the depth of penetration in this tunnel region can be expressed as (Forrestal et al. 1994, Choudhury et al. 2002, Siddqui 2003).

$$
z_{f t}=\frac{m}{2 \pi a^{2} \rho_{c} N} \ln \left(1+\frac{N \rho_{c} V_{c}^{2}}{S f_{c}}\right)+4 a
$$

Putting the value of $V_{c}$ from Eq. (8) in the above equation we get 


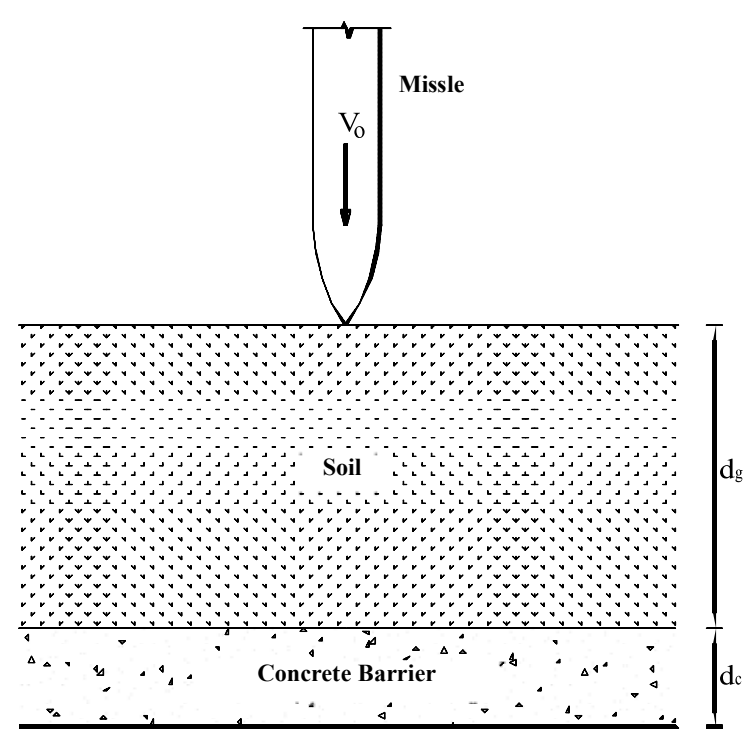

Figure 1. Problem formulation

$$
\begin{aligned}
z_{f t} & =\frac{m}{2 \pi a^{2} \rho_{c} N} \ln \\
& \left(1+\frac{N \rho_{c}}{S f_{c}}\left\{\frac{m\left(\frac{\alpha_{S}}{\beta_{S}}\right) \tan ^{2} B^{\prime}-4 \pi a^{3} S f_{c}}{m+4 \pi a^{3} N \rho_{c}}\right\}\right)+4 a
\end{aligned}
$$

The limit state function $g(\underline{X})$ for this region, measured from the concrete surface, therefore, can be expressed as

$$
g(\underline{X})=d_{c}-z f t
$$

Substituting the expression of $z_{f t}$ from Eq. (17) in Eq. (18) we get the limit state function for the tunnel region as

$$
g(\underline{X})=d_{c}-\left[\begin{array}{l}
\frac{m}{2 \pi a^{2} \rho_{c} N} \ln \\
{\left[1+\frac{N \rho_{c}}{S f_{c}}\left\{\frac{m\left(\frac{\alpha_{S}}{\beta_{S}}\right) \tan ^{2} B^{\prime}-4 \pi a^{3} S f_{c}}{m+4 \pi a^{3} N \rho_{c}}\right\}\right]+4 a}
\end{array}\right]
$$

where, $(\underline{X})$ denotes the same vector of random variable as given by Eq. (15).

Since we have two limits state functions one for the crater region and other for tunnel region to assign an appropriate limit state function for reliability calculations, first we assume that the missile lies in the crater region, and with this assumption we compute crater depth $z_{s c}$. If this crater depth is less than the $4 \mathrm{a}$, the limit state function given by Eq. (14) is used. Otherwise Eq. (19) is employed for reliability calculations.

\section{Reliability Estimation}

Having established the limit state function, the next step is the reliability assessment of the buried concrete target against normal missile impact. For this purpose, a reliability technique known as First Order Reliability Method (FORM) (Melchers 1999) has been employed. A brief description of FORM is provided herein. In brief, in this approach of reliability estimation, the basic random variables $x_{i}(i=1,2, . ., n)$ are first transformed to 'reduced uncorrelated variables' with zero mean and unit variance as

$$
z_{i}=\frac{x_{i}-\mu_{x_{i}}}{\sigma_{x_{i}}}
$$

wherein $\mu_{x}$ and $\sigma_{x}$ are the mean and standard deviations of the variables $x_{i}$. The reliability is measured in terms of a reliability index, $\beta$, which is defined as the shortest distance to the failure surface from the origin in a $z$ coordinate system, and it is related to the probability of failure or probability of limit state violation for any limit state as

$$
\beta=-\Phi^{-1}\left(P_{f}\right)
$$

wherein $P_{f}$ is the failure probability and $\Phi^{-1}($.$) is the$ inverse of standard normal distribution function. The reliability index $\beta$ is found from the solution of the constrained optimization problem:

$$
\begin{aligned}
& \text { Minimize } \beta(\underline{z})=\left(\underline{z}^{T} \underline{z}\right)^{1 / 2} \\
& \text { Subject to } g(\underline{z})=0
\end{aligned}
$$

wherein $\underline{z}$ is a vector of the basic random variables in the standard normal space and $g(\underline{z})$ is the limit state function in the standard normal space. The relevant relations as obtained through the Lagrange multiplier approach for optimization may be summarized as follows:

The most probable failure point/design point/checking point is expressed as

$$
z_{i}^{*}=-\alpha_{i}{ }^{*} \beta
$$

wherein $\alpha_{i}^{*}$ are the direction cosines and given as

$$
\alpha_{i}^{*}=\frac{\left(\frac{\partial g}{\partial z_{i}}\right)_{*}}{\sqrt{\sum_{i}\left(\frac{\partial g}{\partial z_{i}}\right)_{*} 2}}
$$




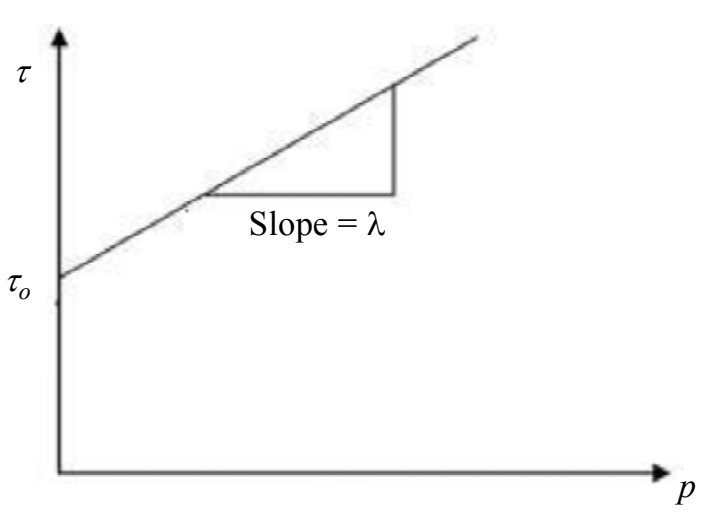

Figure 2. Idealized shear strength-pressure relation for the soil

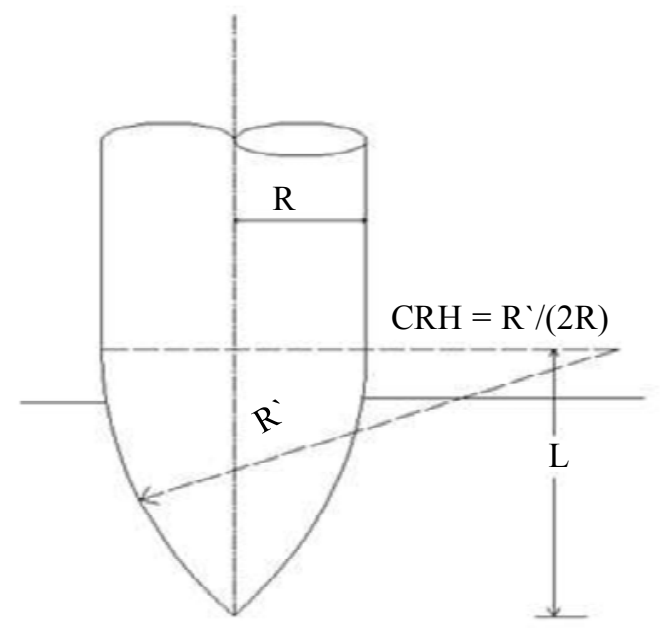

Figure 3. Definition of caliber radius head (CRH)

$$
\begin{aligned}
& x_{i}{ }^{*}=\mu_{x_{i}}-\alpha_{i}{ }^{*} \beta \sigma_{x_{i}} \\
& g\left(x_{1}{ }^{*}, x_{2}{ }^{*}, \ldots \ldots \ldots \ldots . . ., x_{n}{ }^{*}\right)=0
\end{aligned}
$$

The reliability index $\beta$ and design points $z_{i}{ }^{*}$ are evaluated by solving the Eqs. (24) through (27) iteratively for normally distributed variables. If the design variables do not follow normal distribution, the nonnormal probability distributions may be incorporated in the analysis by transforming the non-normal variables into equivalent normal variables. The parameters of the equivalent normal are estimated using the following relations:

$$
\begin{aligned}
& \sigma_{x_{i}}^{N}=\frac{\phi\left\{\Phi^{-1}\left[F_{i}\left(x_{i}^{*}\right)\right]\right\}}{f_{i}\left(x_{i}^{*}\right)} \\
& \mu_{x_{i}}^{N}=x_{i}^{*}-\left[\Phi^{-1}\left(F_{i}\left(x_{i}^{*}\right)\right)\right] \sigma_{x_{i}}^{N}
\end{aligned}
$$

wherein $F_{i}$ and $f_{i}=$ non- normal distribution and density functions of $x^{i}$; and $\Phi$ and $\phi=$ cumulative distribution and probability density functions for standard normal variates respectively.

\subsection{Numerical Algorithm}

A simple numerical algorithm for FORM, as presented by (Nowak and Collins 2000), is provided below.

(i) Formulate the limit state function. Determine the probability distribution and appropriate parameters for all random variables $x_{i}(i=1,2 \ldots \mathrm{n})$

(ii) Obtain an initial design point $\left(x_{i}^{*}\right)$ by assuming values for $n-1$ of the random variables $x_{i}$. Mean values are often a reasonable choice. Solve the limit state equation $g(\underline{x})=0$ for the remaining random variables. This ensures that the design point is on the failure boundary.

(iii) For each of the design point values $x_{i}^{*}$ corresponding to nonnormal distribution, determine the equivalent normal standard deviation and mean using Eqs. (28) and (29). If one and more $x_{i}^{*}$ values corresponds to a normal distribution, then the equivalent normal parameters are simply the actual parameters.

(iv) Find out the reduced variates $\left\{z_{i}^{*}\right\}$ corresponding to the design point $x_{i}^{*}$ using Eq. (20).

(v) Determine the partial derivative of the limit state function with respect to the reduced variates using the equation.

$$
\frac{\partial g}{\partial z_{i}}=\frac{\partial g}{\partial x_{i}} \sigma_{x_{i}}
$$

Define a column vector $\{G\}$ as the vector whose elements are these partial derivatives multiplied by -1

$$
\{G\}=\left\{\begin{array}{l}
G_{1} \\
G_{2} \\
\cdot \\
\cdot \\
G_{n}
\end{array}\right\} ; G_{i}=-\frac{\partial g}{\partial z_{i}}{ }^{*}
$$

(vi) Calculate an estimate of $\beta$ using the following relation

$$
\beta=\frac{\{G\}^{T}\left\{z^{*}\right\}}{\sqrt{\{G\}^{T}\{G\}}} ;\left\{z^{*}\right\}=\left\{\begin{array}{l}
z_{1}^{*} \\
z_{2} \\
\cdot \\
z_{n}^{*}
\end{array}\right\}
$$

(vii) Calculate a column vector containing the sensitivity factors using

$$
\{\alpha\}=\frac{\{G\}}{\sqrt{\{G\}^{T}\{G\}}}
$$


Table 1. Statistical data and random variables

\begin{tabular}{|l|l|l|l|l|}
\hline \multicolumn{1}{|c|}{ Random variables } & \multicolumn{1}{c|}{ D istribution } & \multicolumn{1}{c|}{ M ean } & \multicolumn{1}{c|}{ C OV } & \multicolumn{1}{c|}{ Reference $^{\#}$} \\
\hline Shear strength of soil, $\tau_{o}$ & Normal & $0.5 \mathrm{MPa}$ & 0.30 & Assumed \\
\hline Coefficient of friction, $\mu$ & Normal & 0.085 & 0.10 & Assumed \\
\hline Depth of soil cover, $d_{g}$ & Normal & $10.0 \mathrm{~m}$ & 0.05 & Assumed \\
\hline Modulus of elasticity of soil, $E$ & Normal & $160 \mathrm{MPa}$ & 0.30 & {$[1]$} \\
\hline $\begin{array}{l}\text { Slope of shear strength-pressure curve, } \\
\lambda\end{array}$ & Normal & 0.375 & 0.10 & {$[1]$} \\
\hline Volumetric strain, $\eta^{*}$ & Normal & 0.13 & 0.10 & {$[1]$} \\
\hline Density of concrete target, $\rho_{c}$ & Lognormal & $2.0 \times 10^{4}$ & 0.10 & {$[2]$} \\
\hline $\begin{array}{l}\text { Unconfined comp strength of concrete, } \\
f_{\mathrm{c}}\end{array}$ & Lognormal & $40 \mathrm{MPa}$ & 0.10 & {$[2]$} \\
\hline Thickness of concrete target, $d_{c}$ & Normal & $1.2 \mathrm{~m}$ & 0.05 & Assumed \\
\hline Dimensionless parameter, $S$ & Normal & 11.26 & 0.15 & {$[2]$} \\
\hline Shank radius, $a$ & Normal & $0.165 / 2.0 \mathrm{~m}$ & 0.05 & {$[3]$} \\
\hline Caliber radius head, $\psi$ & Normal & 9.25 & 0.05 & {$[3]$} \\
\hline Missile impact velocity, $V_{o}$ & Extreme type I & $411.0 \mathrm{~m} / \mathrm{s}$ & 0.10 & {$[3]$} \\
\hline Mass of the missile, $m$ & Lognormal & $182.0 \mathrm{~kg}$ & 0.05 & {$[3]$} \\
\hline
\end{tabular}

\#[1]: Forrestal and Luk (1992); [2]: Choudhury et al. (2002); [3]: Siddiqui et al. (2002)

Table 2. Results of the analysis

\begin{tabular}{|c|c|c|}
\hline Estimated Para meter & Present Concrete barrier & Desirable range \\
\hline Probability of failure, $P_{f}$ & $4.90 \times 10^{-2}$ & $10^{-3}-10^{-5}$ \\
\hline Reliability index, $\beta$ & 1.57 & $3-4$ \\
\hline
\end{tabular}

(viii) Determine a new design point in reduced variates for $n-1$ of the variables using

$$
z_{i}^{*}=-\alpha_{i}{ }^{*} \beta
$$

(ix) Determine the corresponding design point values in original coordinates for the $n-1$ values using the relation

$$
x_{i}^{*}=\mu_{x_{i}}^{N}+z_{i}^{*} \sigma_{x_{i}}^{N}
$$

(x) Find out the value of the remaining variable by solving the limit state function $g(\underline{x})=0$.

(xi) Repeat steps (iii) to (x) until $\beta$ and the design point $\left\{x_{i}^{*}\right\}$ converge.

\section{Numerical Study}

To illustrate the application of the present formulation, a solid missile of (Siddiqui et al. 2002) was chosen. This missile had a mass of $182 \mathrm{~kg}$, a shank radius of $0.0825 \mathrm{~m}$ and an impact velocity of $411-\mathrm{m} / \mathrm{s}$. Other statistical data that are needed for reliability assess- ment are presented in Table 1. With these statistical data and using limit state functions (Eqs. 14, 19) the reliability of an underground concrete barrier was evaluated. For this purpose, the algorithm presented above was employed.

\section{Discussion of Results}

Table 2 presents the result of the reliability analysis. The analysis gives the reliability index $(\beta)$ of an underground concrete barrier as 1.66 and its corresponding probability of failure $\left(P_{f}\right)$ as $4.90 \times 10^{-2}$. These values show that the underground concrete barrier is not as reliable as generally desired for structures of importance. This is due to the fact that in a probabilistic design of important strategic structures, a reliability index $(\beta)$ of less than 3 is never chosen (Siddiqui et al. 2003). There is a number of ways to improve the above $\beta$ from 1.66 to a desirable range, eg. by increasing concrete thickness, concrete compressive strength, the shear strength of the soil (by specifying compaction), or by constructing the concrete barrier deeper in the soil. 


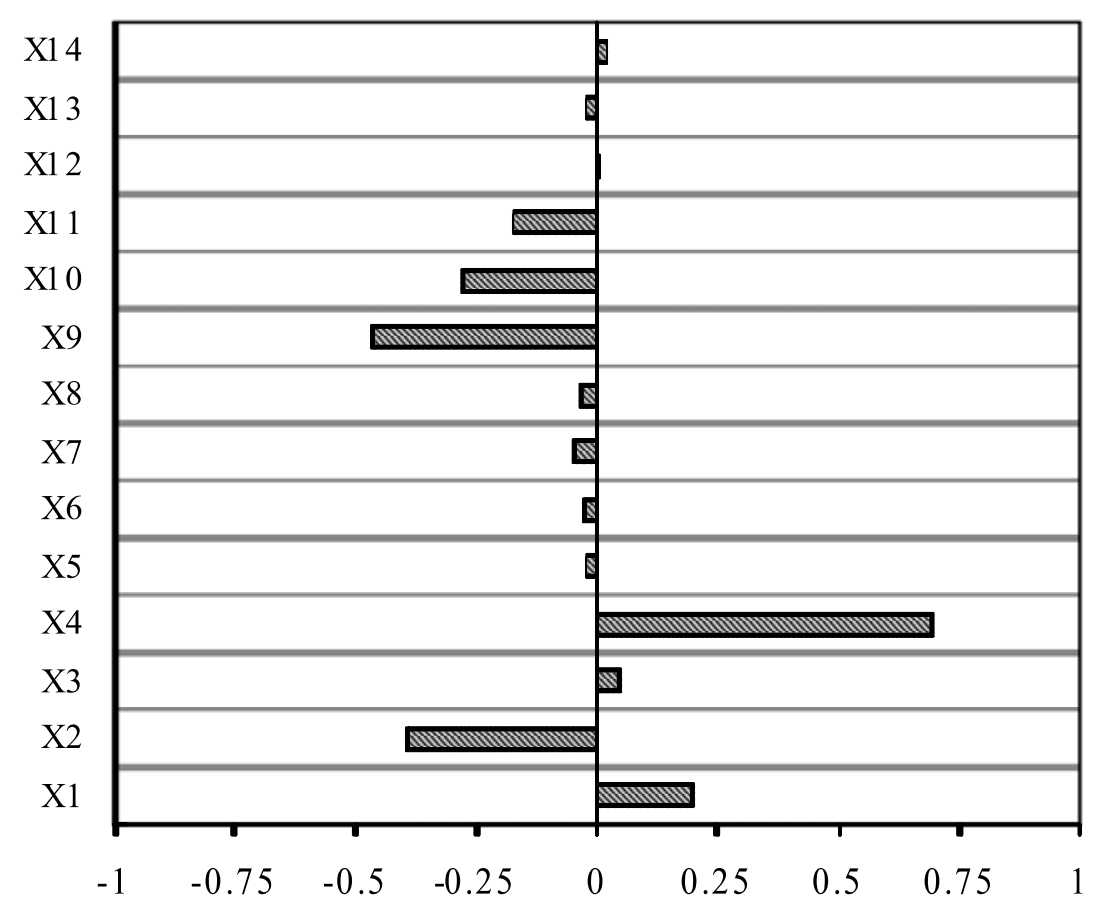

Figure 4. Sensitivity diagram

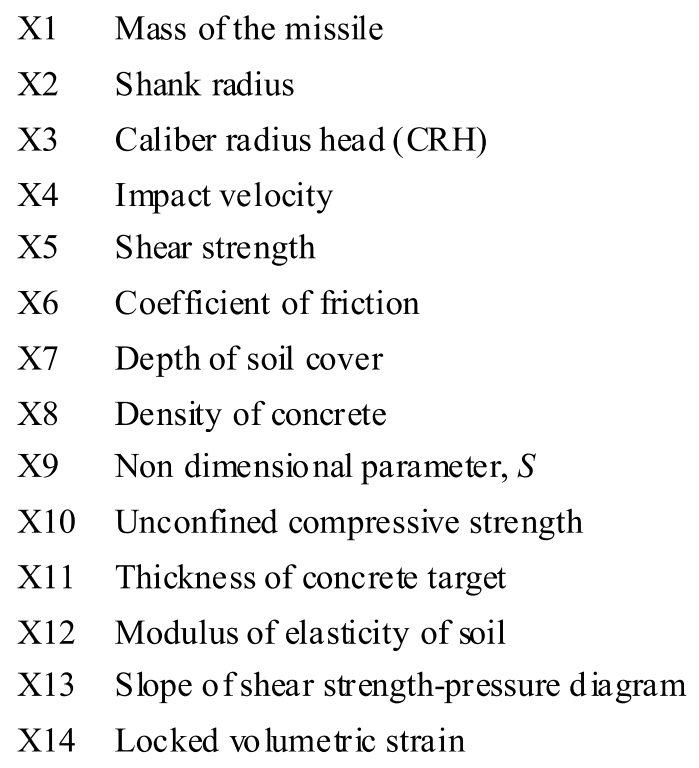

It is to be noted that the desirable range shown in Table 2 was chosen to cover a range which is generally desired to ensure the safety of most important civil engineering structures (Siddiqui 2003, Siddiqui et al. 2003, Khan et al. 2006). However, in practice these values are to be decided for any strucgture on the basis of extensive calibration studies as well as on a consideration of cost issues and the consequences of failure.

\subsection{Sensitivity Analysis}

A sensitivity analysis was carried out to study the influence of various random variables on the reliability of an underground concrete barrier. This influence is measured in terms of sensitivity factor $\left(\alpha_{j}\right)$, defined above in Eqn. (33). The values of sensitivity factors are presented in a bar chart in Fig. 4. This figure shows that the sensitivity factor for missile mass, caliber radius head $(\mathrm{CRH})$ and impact velocity are positive, indicating that an increase in the magnitude of these variables will decrease the concrete barrier reliability. Other random variables are negative, indicating that anincrease in their magnitude will increase the reliability of the underground concrete barrier. Further, 


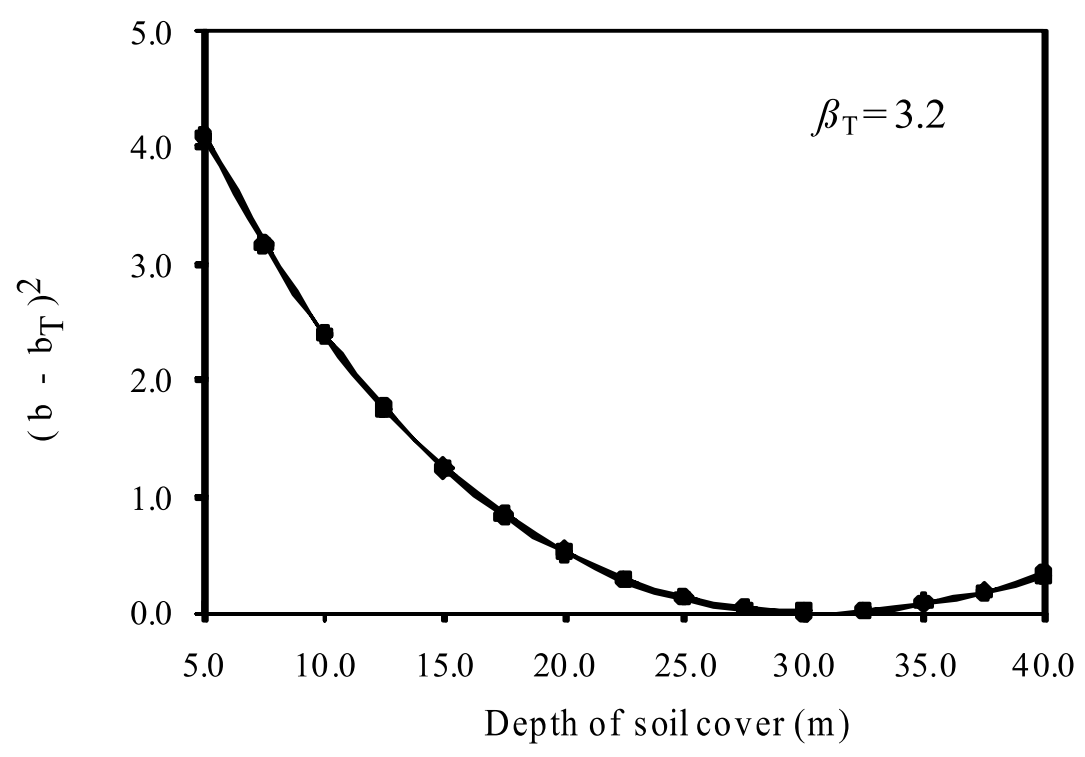

Figure 5. Effect of depth of soil-cover on the reliability of buried concrete target

Fig. 4 points indicates that the missile impact velocity is the most influencing positive variable while the shank radius is the most influencing negative variable. This is due to the fact that as the velocity of a missile increases its penetrating energy increases rapidly whereas with the shank radius of missile resistance offered by soil (or concrete) to missile penetration also increases sharply.

\subsection{Parametric Study}

As the desired reliability for any important structure should range from 3 to 4 , in the present study, some parametric studies were also carried out to illustrate how to achieve the desired reliability by altering the design values of the parameters. For this purpose, a reliability index equals to $3.2\left(\beta_{\mathrm{T}}=3.2\right)$ was selected and the following parametric studies were conducted to obtain the desired value of the chosen parameter to achieve this reliability. Also, for this purpose, the variation of $\left(\beta-\beta_{\mathrm{T}}\right)^{2}$ was studied for different nominal values of the selected parameter. The value of the parameter for which $\left(\beta-\beta_{\mathrm{T}}\right)^{2}$ is close to zero, yields the value of the parameter which makes the barrier as reliable as desired.

\subsubsection{Effect of Depth of Soil Cover}

In the present study, the concrete barrier was placed at $10 \mathrm{~m}$ under the soil cover. This overlying soil acted as energy dissipater to the missile. If a concrete barrier is placed in deeper soil, the missile will lose more of its energy before hitting the concrete barrier and thus the reliability of the concrete barrier will improve. Figure 5 shows that when depth of the soil cover reaches $30 \mathrm{~m}$, the concrete-barrier reliability increases to the desired reliability of 3.2. If constructing the concrete barrier at this depth is a feasible and an economical option then this option may be selected in order to achieve the desired reliability. Otherwise, designers may consider some other parameters, discussed below, along with this one to achieve the desired reliability.

\subsubsection{Effect of Unconfined Compressive Strength of Concrete}

Since the unconfined compressive strength of concrete offers resistance to missile penetration, an increase in its value will correspondingly increase the resistance to missile penetration. Based on the principle " the less the penetration the more the reliability", one can say that the barrier reliability will increase with an increase in the compressive strength of concrete. Figure 6 shows that to achieve the desired reliability (keeping other parameters same as given in Table 1) the compressive strength of the concrete should be at least equals to $70 \mathrm{MPa}$. If to construct a concrete barrier with compressive strength above 70 $\mathrm{MPa}$ is very expensive then to achieve a desirable range of reliability index $\left(\beta_{\mathrm{T}}=3.2\right)$ it is better to increase the strength of the concrete along with other feasible parameters such as the thickness of concrete barrier, depth of the soil cover, shear strength (by specifying compaction) etc.

\subsubsection{Effect of Concrete Thickness}

In the present study an underground concrete barrier is said to have failed if a given missile completely 


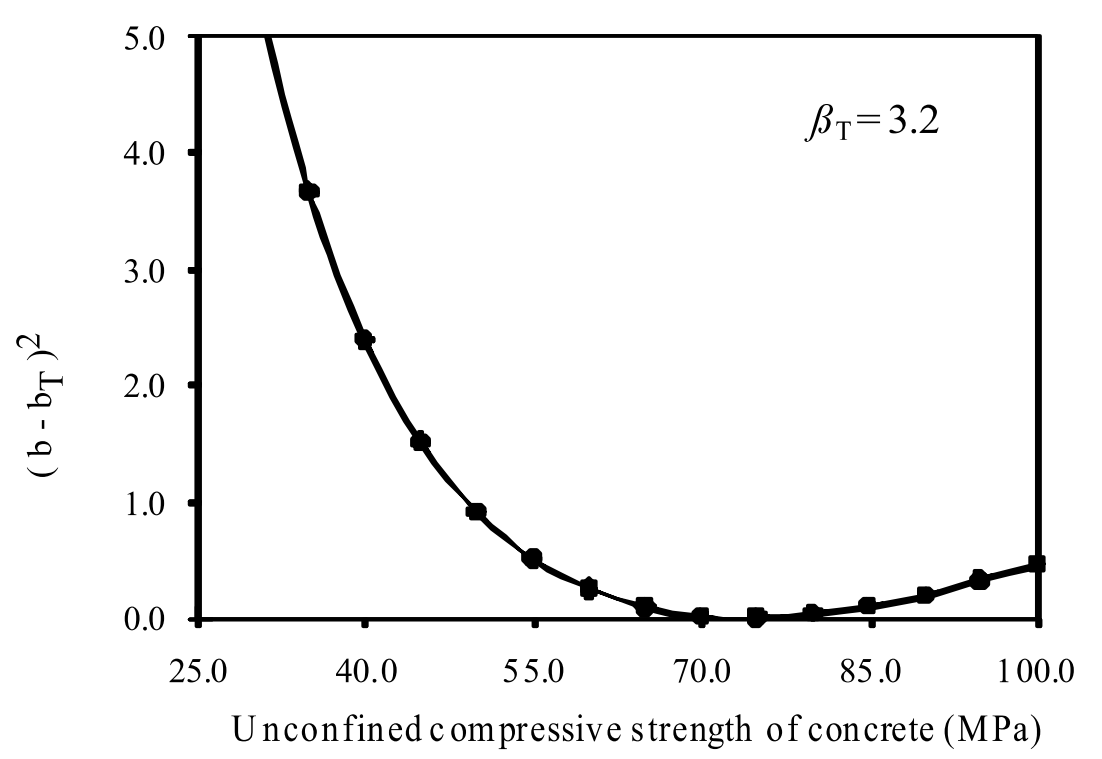

Figure 6. Effect of compressive strength of concrete on the reliability of buried concrete target

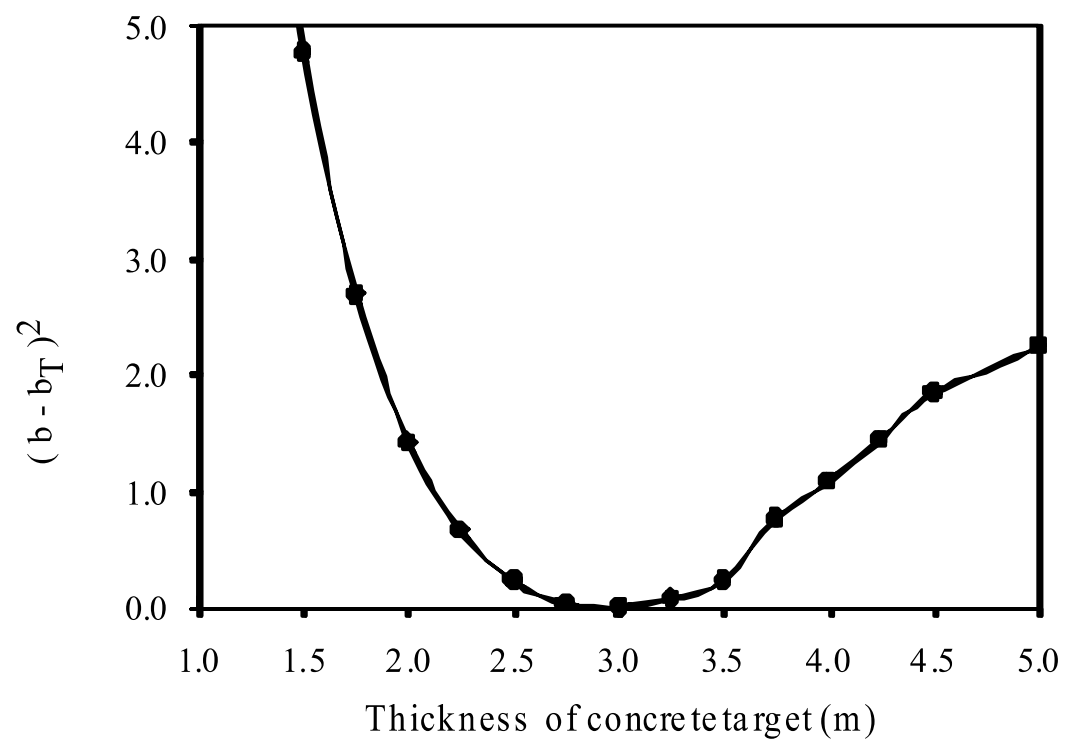

Figure 7. Effect of concrete thickness on the reliability of buried concrete target

penetrates the barrier. It is strongly expected that as the thickness of the concrete barrier increases, the reliability will increase. Figure 7 shows that to achieve the desired reliability of $3.2\left(\beta_{\mathrm{T}}=3.2\right)$, the concrete thickness should not be less than $3.0 \mathrm{~m}$. As increasing the thickness of concrete barrier is quite an expensive option, it is better to also consider other parameters along with the thickness to reach the desired reliability.

\subsubsection{Effect of Missile Velocity}

The velocity of a missile is a measure of its kinetic energy. If its velocity increases it will have more impact energy and thus more penetration power. For this reason, it is expected that as the impact velocity increases the reliability of concrete barrier decreases. Figure 8 shows that the present concrete barrier is reliable enough if the impacting velocity of the missile is less than $300 \mathrm{~m} / \mathrm{s}$. If concrete barrier is expected to receive missiles with higher velocities, its reliability should be improved by altering its design parameters, as discussed above. 


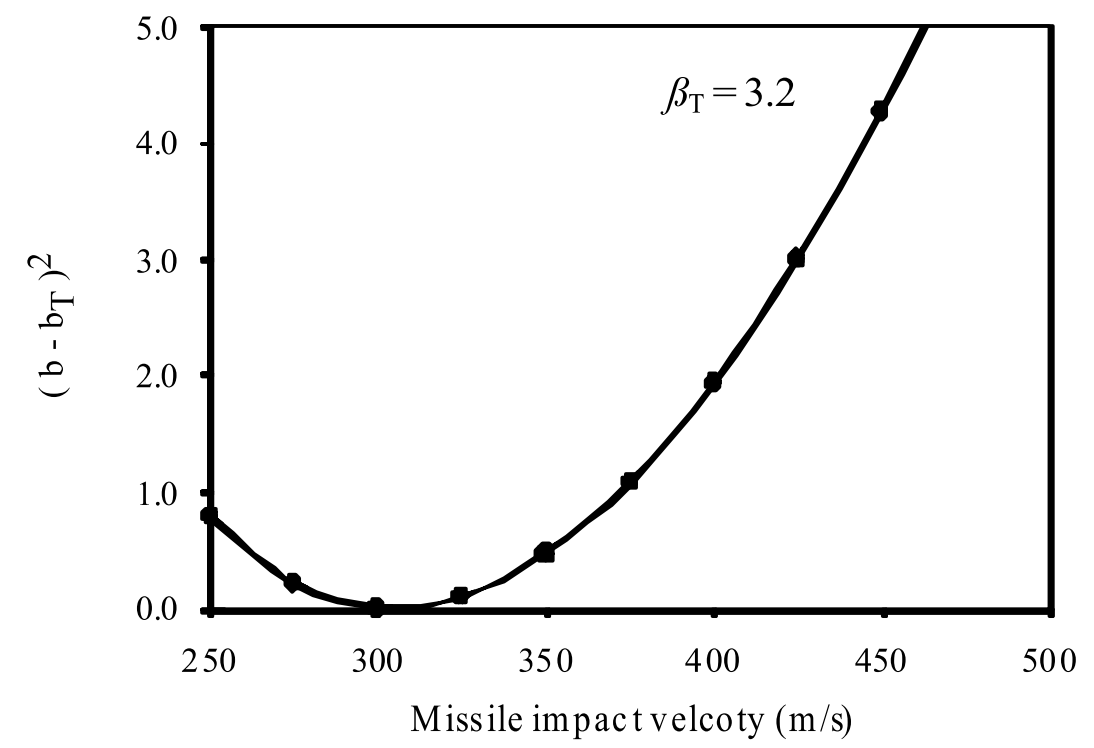

Figure 8. Effect of missile velocity on the reliability of buried concrete target

\section{Conclusions}

In this paper a simple procedure for the reliability estimation of underground concrete barriers against the normal impact of a missile has been presented. The presented procedure was applied to a numerical example to estimate its reliability. Some parametric studies were also conducted to illustrate how to achieve the desired reliability by altering the design values of the parameters. For this purpose, a reliability index equals to $3.2\left(\beta_{\mathrm{T}}=3.2\right)$ was selected and analysis was done to obtain the design value of the chosen parameter to achieve this reliability. The variation of $\left(\beta-\beta_{\mathrm{T}}\right)^{2}$ was studied for different nominal values of the selected parameter. The value of the parameter for which $\left(\beta-\beta_{\mathrm{T}}\right)^{2}$ is close to zero, yields the value of the parameter which makes the barrier as reliable as desired. To demonstrate the relative influence of various random variables (design parameters) on barrier reliability a sensitivity diagram was also shown.

\section{Acknowledgment}

The work presented in this paper was supported by the Deanship of Scientific Research, Research Centre, College of Engineering, King Saud University, Riyadh, Saudi Arabia.

\section{References}

Choudhury, M.A., Siddiqui, N.A. and Abbas, H., 2002, "Reliability Analysis of a Buried Concrete
Target under Missile Impact," Int. J. of Impact Engineering. Vol. 27, pp. 791-806.

Forrestal, M. J. and Luk, V. K., 1992, "Penetration into Soil Targets," Int. J. of Impact Engineering, Vol. 12, pp. 427-444.

Forrestal, M. J., Altman, B. S., Cargile, J. D. and Hanchak, S. J., 1994, "An Empirical Equation for Penetration Depth of Ogive-nose Projectiles into Concrete Target." Int. J. of Impact Engineering, Vol. 15(4), pp. 395-405.

Forrestal, M. J., Frew, D. J., Hanchak, S. J. and Bar, N. S., 1996, "Penetration of Grout and Concrete Target with Ogive-nose Steel Projectiles," Int. J. of Impact Engineering, Vol.18(5), pp. 465-476.

Forrestal, M. J., Frew, D. J., Hickerson, J. P. and Rohwer, T. A., 2003, "Penetration of Concrete Targets with Deceleration-time Measurements." Int. J. of Impact Engineering, Vol. 28, pp. 479497.

Frew, D. J., Hanchak, S. J., Green, M. L. and Forrestal, M. J., 1998, "Penetration of Concrete Target with Ogive-nose Steel Rods," Int. J. of Impact Engineering, Vol. 21(6), pp. 489-497.

Frew, D. J., Forrestal, M. J. and Cargile, J. D., 2006, "The Effect of Concrete Target Diameter on Projectile Deceleration and Penetration Depth," Int. J. of Impact Engineering, Vol. 32, pp.15841594.

Khan, U., Siddiqui, N.A., Umar, A. and Abbas, H., 2003, "Local Damage in Concrete Targets under Impact Load," Defence Science Journal, DRDO, India, Vol. 53(1), pp. 67-73.

Khan, R.A., Siddiqui, N. A., Naqvi, S.Q.A. and Ahmad, S., 2006, "Reliability Analysis of TLP 
Tethers under Impulsive Loading." Reliability Engineering and System Safety, Vol. 91(1), pp. 73-83.

Melchers, R.E., 1999, "Structural Reliability Analysis and Prediction," John Wiley and Sons, Second Edition, 1999, USA.

Nowak, A.S. and Collins, K.R., 2000, "Reliability of Structures," Mc Graw Hill, Singapore.

Siddiqui, N.A., Choudhury, M.A. and Abbas, H., 2002, "Reliability Analysis of Projectile Penetration into Geological Targets," Reliability Engineering and System Safety, Vol. 78, pp. 1319.

Siddiqui, N.A. and Abbas, H., 2002, "Mechanics of Missile Penetration Into Geo-materials," Structural Engineering and Mechanics, An International Journal, Vol. 13(2), pp. 639-652.
Siddiqui, N.A., 2003, "Reliability Analysis of Concrete Barriers under Normal Missile Impact," Proceedings of National Conference on Advances in Civil Engineering: Perspectives of Developing Countries (ACEDEC 2003), HBTI Kanpur, India, 15-16 January, Vol. 1, pp. 20-29.

Siddiqui, N.A., Iqbal, M.A., Abbas, H. and Paul, D.K., 2003, "Reliability Analysis of Nuclear Containment without Metallic Liners against Jet Aircraft Crash." Nuclear Engineering and Design, Vol. 224, pp. 11-21.

Siddiqui, N. A., Kumar, S., Khan, M. A. and Abbas, H., 2006, "A Simplified Procedure to Incorporate Soil Nonlinearity in Missile Penetration Problems," Structural Engineering and Mechanics, An International Journal, Vol. 23(3), pp. 249-262. 


\section{Appendix}

Parameters $\alpha_{s}$ and $\beta_{s}$ :

$$
\left.\begin{array}{l}
\alpha_{s}=\pi a^{2} \tau_{o} A\left[1+4 \mu \psi\left(\frac{\pi}{2}-\theta_{o}\right)-\mu(2 \psi-1)(4 \psi-1)^{1 / 2}\right] \\
\beta_{s}=\pi a^{2} \rho_{o} B\left[\frac{(8 \psi-1)}{24 \psi^{2}}+\mu \psi^{2}\left(\frac{\pi}{2}-\theta_{o}\right)-\frac{\mu(2 \psi-1)\left(6 \psi^{2}+4 \psi-1\right)(4 \psi-1)^{1 / 2}}{24 \psi^{2}}\right] \\
\theta_{0}=\operatorname{Sin}^{-1}\left(\frac{2 \psi-1}{2 \psi}\right) \\
A=\frac{1}{\alpha}\left(\frac{1+\tau_{o} / 2 E}{\gamma}\right)^{2 \alpha}-\frac{1}{\lambda} \\
B=\frac{\left(1-\eta^{*}\right)(1-2 \alpha)(2-\alpha)}{\gamma^{2}}\left(\frac{1+\tau_{o} / 2 E}{\gamma}\right)^{2 \alpha} \times \\
\frac{3 \tau_{o}}{E}+\eta^{*}\left(1-3 \tau_{o} / 2 E\right)^{2}-\frac{\gamma^{3}\left[2\left(1-\eta^{*}\right)(2-\alpha)+3 \gamma^{3}\right]}{\left(1-\eta^{*}\right)(1-2 \alpha)(2-\alpha)\left(1+\frac{\tau_{o}}{2 E}\right)^{4}}
\end{array}\right\}
$$

$E=$ Young's modulus of elasticity of soil; $\eta^{*}=$ volumetric strain; $\rho_{o}=$ initial density of soil; $\mu=$ coefficient of friction; and $\psi=$ Caliber Radius Head $(\mathrm{CRH}) . \mathrm{CRH}$ is defined as ratio of radius of missile nose to the diameter of missile aft body as shown in Fig. 3.

Derivation of $V_{z}$ as a function of penetration depth $z$ :

Integration of Eq. (2) with the initial condition $V=V_{0}$ gives, velocity, acceleration and depth of penetration at any time $t$ : 


$$
\begin{aligned}
& V_{z}=\left(\frac{\alpha_{s}}{\beta_{s}}\right)^{1 / 2} \tan \left\{\tan ^{-1}\left[\left(\frac{\beta_{s}}{\alpha_{s}}\right)^{1 / 2} V_{o}\right]-\frac{\left(\alpha_{s} \beta_{s}\right)^{1 / 2} t}{m}\right\} \\
& \frac{d V z}{d t}=-\frac{\left(\alpha_{s} / m\right)}{\operatorname{Cos}^{2}\left\{\tan ^{-1}\left(\frac{\beta_{s}}{\alpha_{s}}\right)^{1 / 2} V_{o}-\frac{\left(\alpha_{s} \beta_{s}\right)^{1 / 2}}{m} t\right\}}
\end{aligned}
$$

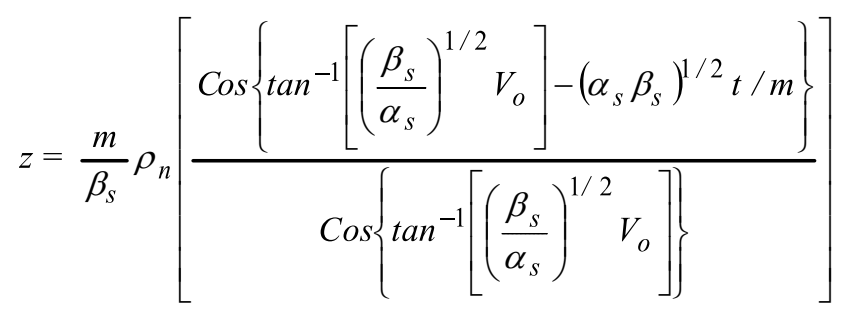

After rearranging Eq. (A-10), we get the expression for time $t$ in terms of $z$ as

$$
t=\frac{m}{\left(\alpha_{S} \beta_{S}\right)^{1 / 2}}\left[A^{\prime}-\operatorname{Cos}^{-1}\left\{\operatorname{Cos} A^{\prime} \times \exp \left(z \frac{\beta_{S}}{m}\right)\right\}\right]
$$

where $A^{\prime}=\tan ^{-1}\left[\left(\frac{\beta_{s}}{\alpha_{s}}\right)^{1 / 2} V_{o}\right]$

Sub stituting the value of $t$ from Eq. (A-11) into Eq. (A-8) we get another expression of $V_{z}$ as a function of penetration depth $z$ as,

$$
\begin{aligned}
& V_{z}=\left(\frac{\alpha_{s}}{\beta_{s}}\right)^{1 / 2} \tan \left\{\operatorname{Cos}^{-1}\left(\operatorname{Cos} A \times \exp \left(z \frac{\beta_{s}}{m}\right)\right)\right\} \\
& V_{z}=\left(\frac{\alpha_{s}}{\beta_{s}}\right)^{1 / 2} \tan B^{\prime}
\end{aligned}
$$

where $B^{\prime}=\operatorname{Cos}^{-1}\left(\operatorname{Cos} A^{\prime} \times \exp \left(z \frac{\beta_{S}}{m}\right)\right)$ 